\title{
Predictive factors for gangrene complication in acute calculous cholecystitis
}

\author{
Bader Hamza Shirah", Hamza Asaad Shirah², Muhammad Adnan Saleem², \\ Mohammad Azam Chughtai ${ }^{3}$, Mohamed Ali Elraghi ${ }^{3}$, and Mohamed Elsayed Shams ${ }^{4}$
}

\begin{abstract}
${ }^{1}$ King Abdullah International Medical Research Center/King Saud Bin Abdulaziz University for Health Sciences, Jeddah, Departments of ${ }^{2}$ General Surgery and ${ }^{3}$ Radiology, Al Ansar General Hospital, ${ }^{4}$ Department of Surgery, Faculty of Medicine, Taibah University, Medina, Saudi Arabia
\end{abstract}

\begin{abstract}
Backgrounds/Aims: Gallbladder gangrene is a grave complication of acute calculous cholecystitis that is difficult to detect preoperatively. Ultrasound could show a gallbladder wall that is more thickened. In addition, other clinical measures were reported to be possible predictive factors. Therefore, we aim in this study to evaluate the gallbladder wall thickness measured by ultrasound and other clinical measures as predictive factors for gangrene complication in acute calculous cholecystitis. Methods: A prospective cohort database analysis of the results of 674 patients diagnosed and treated for acute calculous cholecystitis between January 2010 and December 2014 was done. Patient's inclusion criteria were acute calculous cholecystitis in adults who were operated within three days of onset of symptoms. Results: $117(17.4 \%)$ patients had gangrene. Gallbladder sonographic wall thickness 5.1-6 mm, more than $6 \mathrm{~mm}$, male gender, diabetes mellitus, leukocytosis $>15,000$ cells $/ \mathrm{ml}$, and age $\geq 40$ years were found to be factors predisposing to gangrene complicated acute calculous cholecystitis that represented a statistically significant difference $(p \leq 0.01)$. Conclusions: We conclude that gallbladder sonographic wall thickness 5.1-6 mm, more than $6 \mathrm{~mm}$, male gender, diabetes mellitus, leukocytosis $>15,000$ cells $/ \mathrm{ml}$, and age $\geq 40$ years were found to be factors predisposing to gangrene complicated acute calculous cholecystitis that represented a statistically significant difference. By implementing these risk factors, patients urgency for surgery can be decided in the emergency department. Other risk factors such as high alanine aminotransferase, elevated aspartate aminotransferase, and high alkaline phosphatase could be of help in the decision for early operation. (Ann Hepatobiliary Pancreat Surg 2019;23:228-233)
\end{abstract}

Key Words: Acute calculous cholecystitis; Complications; Risk factors; Gangrene of the gallbladder; Gallbladder wall thickness; Ultrasound

\section{INTRODUCTION}

The most serious consequence of acute inflammation of delayed or neglected acute calculous cholecystitis is gangrene of the gallbladder which shows necrosis and perforation of the gallbladder wall as a result of ischemia following progressive vascular insufficiency. It has an incidence range of 2 to $18 \%$ and a mortality rate between $15 \%$ and $50 \%{ }^{1-3}$ Several clinical studies had proven that early cholecystectomy played a useful role in preventing this complication. A delay in the operative intervention is a serious issue. The so-called golden hours of operation
(72-96 hours) since the onset of the symptoms had lowered the complication rates, reduced the conversion rates, shortened the hospital stays, and avoided complications. To achieve that goal, patient's priority for surgery for emergency operation should be done early, even during the preadmission period, in the emergency department. ${ }^{4,5}$

Diagnosis of gangrenous cholecystitis is quite challenging in the preoperative period. The advancement in real-time ultrasound techniques with an accuracy rate more than $95 \%$ in diagnosing acute calculous cholecystitis had facilitated the decision-making process, especially in difficult cases, and resulted in the prompt initiation of the sup-

Received: December 31, 2018; Revised: February 20, 2019; Accepted: February 21, 2019

Corresponding author: Bader Hamza Shirah

King Abdullah International Medical Research Center/King Saud Bin Abdulaziz University for Health Sciences, P.O.Box: 65362, Jeddah 21556, Saudi Arabia

Tel: +966506201963, E-mail: shirah007@ksau-hs.edu.sa

Copyright (C) 2019 by The Korean Association of Hepato-Biliary-Pancreatic Surgery

This is an Open Access article distributed under the terms of the Creative Commons Attribution Non-Commercial License (http://creativecommons.org/ licenses/by-nc/4.0) which permits unrestricted non-commercial use, distribution, and reproduction in any medium, provided the original work is properly cited. Annals of Hepato-Biliary-Pancreatic Surgery • pISSN: 2508-5778 - eISSN: 2508-5859 
portive medical treatment, and an earlier operation option. ${ }^{6-8}$ Many clinical studies have observed that gangrene complicating acute calculous cholecystitis had a male preponderance compared to females with acute cholecystitis. In addition, ultrasound can show a gallbladder wall more thickened in these patients, most of them reported more than $5 \mathrm{~mm}$ thickness, which was considered as a predictive factor for the diagnosis of these complications. ${ }^{9-12}$ Therefore, we aim in this study to evaluate the gallbladder wall thickness measured by ultrasound and other clinical measures as predictive factors for gangrene complication in acute calculous cholecystitis.

\section{MATERIALS AND METHODS}

A prospective cohort database analysis of the results of 674 patients who were diagnosed and treated for acute calculous cholecystitis between January 2010 and December 2014 in Al Ansar general public health hospital in Medina, Saudi Arabia was done. The ethical approval was granted by Al Ansar general hospital ethical committee and the clinical management guidelines and the clinical pathway subcommittee of the quality care program at the same hospital.

Patients inclusion criteria were acute calculous cholecystitis in adults (age 12 years and above as per the national health policy), who presented to the emergency department, diagnosed by ultrasound, and were admitted and operated within three days of onset of symptoms. Patients proven to have had perforated gallbladder due to complicated acute cholecystitis were excluded from the analysis because of the different ultrasonographic features reported. In addition, cases of chronic and acalculous cholecystitis were excluded. The ultrasound method used was unified to all radiologists by a clinical pathway protocol guidelines. A digital structured data file was used to register all ultrasound data. The unified protocol included using the same ultrasound machine brand, the same probes type (linear and curvilinear), the same frequencies, and a unified approach and examination technique.

Presenting symptoms, vital signs, positive abdominal signs, ultrasound report, comorbid disease, the interval between onset of symptoms and operation, gallbladder pathology and complications, patient age, gender, and histopathological findings were the criteria tested in all patients and were recorded on a computerized database sheet. Gangrenous gallbladder was detected from the histopathology report.

The correlation of incidence of acute calculous cholecystitis complication gangrene to the sonographic gallbladder wall thickness and other clinical factors was tested, and data analysis was structured. A digital database file was used to document the whole patient's data. Statistical Package for Social Science (SPSS) program (release 22) was used for data analysis. Results were represented by percentages and mean. The variables with a $p$-value $\leq 0.01$ were considered to represent a significant difference statistically.

\section{RESULTS}

Between January 2010 and December 2014, 674 patients who were diagnosed and treated for acute calculous cholecystitis were included. 265 (39.3\%) were males and 409 (60.7\%) were females. Complicated acute calculous cholecystitis data, as evident by histopathology confirmation, showed that $117(17.4 \%)$ patients had gangrene. Among them, $74(63.2 \%)$ were males and $43(36.8 \%)$ females. Male to female ratio was 1.7:1. The incidence of gangrene in our study was $11.5 \%$. Male gender was found statistically to represent a significant difference for the association with gangrene $(p=0.04)$.

The mean age of the male patients was $42.6 \pm 11$ years while it was $39.2 \pm 8$ years in the female patients. Age $\geq 40$ years was found statistically to represent a significant difference for both males and females $(p=0.04)$. Right, upper quadrant pain was the dominant presenting complaints $(100 \%)$, and right upper quadrant tenderness was the dominant sign on physical examination $(100 \%)$ while fever was the dominant recorded vital sign change in $96(82.1 \%)$ patients compared to 437 (78.5\%) patients in the non-gangrenous group (Table 1).

Diabetes mellitus was the dominant comorbid disease reported in $73(62.4 \%)$ and 287 (51.5\%) patients in the nongangrene group. Diabetes mellitus was found statistically to represent a significant difference for both males and females $(p=0.02)$. Leukocytosis was the dominant laboratory value change in 107 (91.5\%) patients and 384 (68.9\%) patients in the non-gangrene group. Leukocytosis $>15,000$ cells/ml was found statistically to represent a significant 
Table 1. Personal and clinical data of the patients in the gangrenous compared to non-gangrenous acute calculous cholecystitis groups

\begin{tabular}{lcr}
\hline \multicolumn{1}{c}{ Data } & $\begin{array}{c}\text { Gangrenous } \\
\text { group }\end{array}$ & $\begin{array}{c}\text { Non-gangrenous } \\
\text { group }\end{array}$ \\
\hline Patients No. & $117(100 \%)$ & $557(100 \%)$ \\
Age & $11(9.4 \%)$ & $231(41.5 \%)$ \\
$20-40$ & $71(60.7 \%)^{*}$ & $272(48.8 \%)$ \\
$41-60$ & $35(29.9 \%)^{*}$ & $54(9.7 \%)$ \\
$>60$ & & \\
Symptoms duration & $2(1.7 \%)$ & $85(15.3 \%)$ \\
1 day & $89(76.1 \%)$ & $281(50.4 \%)$ \\
2 days & $26(22.2 \%)$ & $191(34.3 \%)$ \\
3 days & $117(100 \%)$ & $557(100 \%)$ \\
Presenting symptoms & $74(63.2 \%)$ & $300(53.9 \%)$ \\
RUQ pain & $94(80.3 \%)$ & $416(74.7 \%)$ \\
Nausea & & \\
Vomiting & $96(82.1 \%)$ & $365(65.5 \%)$ \\
Physical signs & $117(100 \%)$ & $420(75.4 \%)$ \\
Fever & $110(94 \%)$ & $386(69.3 \%)$ \\
RUQ tenderness & $19(16.2 \%)$ & $77(13.8 \%)$ \\
+ve Murphy's sign & &
\end{tabular}

RUQ, right upper quadrant

*Factors predisposing to gangrene complicated acute calculous cholecystitis that represented a statistically significant difference

Table 2. Comorbidity data of the patients in the gangrenous compared to non-gangrenous acute calculous cholecystitis groups

\begin{tabular}{lcr}
\hline \multicolumn{1}{c}{ Disease } & $\begin{array}{c}\text { Gangrenous } \\
\text { group }\end{array}$ & $\begin{array}{c}\text { Non-gangrenous } \\
\text { group }\end{array}$ \\
\hline Diabetes mellitus & $73(62.4 \%)^{*}$ & $157(28.2 \%)$ \\
Bronchial asthma & $20(17.1 \%)$ & $78(14 \%)$ \\
Hypertension & $37(30.8 \%)$ & $192(34.5 \%)$ \\
Ischemic heart dis. & $11(9.4 \%)$ & $43(7.75 \%)$ \\
Hypercholesterolemia & $41(35 \%)$ & $245(44 \%)$ \\
Thyroid diseases & $3(2.6 \%)$ & $23(4.1 \%)$ \\
Anemia & $25(21.4 \%)$ & $148(26.6 \%)$ \\
\hline
\end{tabular}

*Factors predisposing to gangrene complicated acute calculus cholecystitis that represented a statistically significant difference

difference for both males and females $(p=0.03)$ (Tables 2, 3).

Gallbladder stone was the dominant reported ultrasound feature in $(100 \%)$ patients. Gallbladder wall thickness of acute calculous cholecystitis cases data showed that 54 (8\%) had sonographic wall thickness between 3-4 mm. Among them, 0 (0\%) had gangrene. 124 (18.4\%) had sonographic wall thickness 4.1-5 mm. Among them, 2 (0.3\%) had gangrene. 389 (57.7\%) had sonographic wall thickness 5.1-6 mm. Among them, 94 (13.9\%) had gangrene.
Table 3. Laboratory data of the patients in the gangrenous compared to non-gangrenous acute calculous cholecystitis groups

\begin{tabular}{lcr}
\hline \multicolumn{1}{c}{ Laboratory test } & $\begin{array}{c}\text { Gangrenous } \\
\text { group }\end{array}$ & $\begin{array}{c}\text { Non-gangrenous } \\
\text { group }\end{array}$ \\
\hline High WBC & $107(91.5 \%) *$ & $384(68.9 \%)$ \\
$>15,000$ cells/ml & & \\
High ALT $\geq 50 \mathrm{U} / \mathrm{L}$ & $89(76.1 \%)$ & $357(64.1 \%)$ \\
High AST $\geq 43 \mathrm{U} / \mathrm{L}$ & $86(73.5 \%)$ & $346(62.1 \%)$ \\
High ALK.P $\geq 200 \mathrm{U} / \mathrm{L}$ & $67(57.3 \%)$ & $329(59.1 \%)$ \\
High Amylase $\geq 140 \mathrm{U} / \mathrm{L}$ & $21(17.9 \%)$ & $64(11.5 \%)$ \\
High total bilirubin & $28(23.9 \%)$ & $91(16.3 \%)$ \\
$\geq 1.2 \mathrm{mg} / \mathrm{dl}$ & & \\
\hline
\end{tabular}

WBC, white blood cell; ALT, alanine aminotransferase; AST, aspartate aminotransferase; ALK.P, alkaline phosphatase *Factors predisposing to gangrene complicated acute calculus cholecystitis that represented a statistically significant difference

Table 4. Ultrasound data of the patients in the gangrenous compared to non-gangrenous acute calculous cholecystitis groups

\begin{tabular}{lrc}
\hline \multicolumn{1}{c}{ Ultrasound finding } & $\begin{array}{c}\text { Gangrenous } \\
\text { group }\end{array}$ & $\begin{array}{c}\text { Non-gangrenous } \\
\text { group }\end{array}$ \\
\hline Gallstone & $117(100 \%)$ & $557(100 \%)$ \\
Single small & $22(18.8 \%)$ & $66(11.8 \%)$ \\
Multiple small & $69(58.9 \%)$ & $326(58.5 \%)$ \\
Single large & $26(22.2 \%)$ & $165(29.6 \%)$ \\
Distended gallbladder & $112(95.7 \%)$ & $482(86.5 \%)$ \\
$\quad(>5 \mathrm{~cm}$ in diameter) & & $376(67.5 \%)$ \\
Gallbladder wall & 0 & $131(23.5 \%)$ \\
$\quad$ thickness (3-4 mm) & & $44(7.9 \%)$ \\
$(4.1-5 \mathrm{~mm})$ & $2(1.7 \%)$ & 0 \\
$\begin{array}{l}5.1-6 \mathrm{~mm}) \\
\text { (More than 6 mm) }\end{array}$ & $21(17.9 \%)^{*}$ & \\
Pericholecystic fluid & $111(94.8 \%)$ & $433(77.7 \%)$ \\
\hline
\end{tabular}

*Factors predisposing to gangrene complicated acute calculus cholecystitis that represented a statistically significant difference

$127(18.8 \%)$ had sonographic wall thickness more than 6 $\mathrm{mm}$. Among them, $21(3.1 \%)$ had gangrene. The results showed significant correlation for wall thickness 5.1-6 $\mathrm{mm}(p=0.01)$, and more than $6 \mathrm{~mm}(p=0.01)$ (Table 4).

All patients were operated within three days of the onset of symptoms with an average time of $2.1 \pm 0.6$ days for patients in the gangrene group and $2.1 \pm 0.2$ days for the patients in the non-gangrene group.

Gallbladder sonographic wall thickness 5.1-6 mm, more than $6 \mathrm{~mm}$, male gender, diabetes mellitus, leukocytosis $>15,000$ cells $/ \mathrm{ml}$, and age $\geq 40$ years were found to be factors predisposing to gangrene complicated acute calculous cholecystitis that represented a statistically significant 
difference. Other predisposing factors (high alanine aminotransferase, elevated aspartate aminotransferase, and high alkaline phosphatase) were also found to be possible predictors for a complicated acute calculous cholecystitis but not representing a statistically significant difference (Table 5).

\section{DISCUSSION}

In the last few years, the average annual number of gallbladder diseases patients attending the emergency department in our hospital was 400-600 per year. Accordingly, it resulted in an increase in the surgical procedures

Table 5. Comparison between our study and other studies regarding predictive factors to gangrene complicated acute calculous cholecystitis

\begin{tabular}{lccc}
\hline \multicolumn{1}{c}{ Factors } & $\begin{array}{c}\text { Our study } \\
(p \text {-value })\end{array}$ & $\begin{array}{c}\text { Yacoub } \\
\text { et al. } \\
\text { study }\end{array}$ & $\begin{array}{c}\text { Wu } \\
\text { et al. } \\
\text { study }\end{array}$ \\
\hline Male gender & $(p=0.04)$ & $*$ & $*$ \\
Age $\geq 40$ years & $(p=0.04)$ & $*$ & $*$ \\
Diabetes mellitus & $(p=0.02)$ & - & - \\
Leukocytosis $>15,000 \mathrm{cells} / \mathrm{ml}$ & $(p=0.03)$ & $*$ & $*$ \\
Wall thickness 5.1-6 mm & $(p=0.01)$ & $*$ & $*$ \\
Wall thickness more than $6 \mathrm{~mm}$ & $(p=0.01)$ & - & - \\
Heart rate & - & $*$ & - \\
Pericholecystic fluid & - & - & $*$ \\
American Society of & - & - & $*$ \\
Anesthesiology score of $>2$ & & & \\
\hline
\end{tabular}

*Positive factor, -not included performed to about 6-12 operations per week. As a consequence, a series of research studies and clinical pathway guidelines to improve the treatment outcome were initiated. That was the main reason behind this study which changed our protocol and clinical pathway in dealing with both elective and emergency acute cholecystitis cases.

In our study, 117 (17.4\%) patients with acute calculous cholecystitis had related complications in the form of gangrene. Nevertheless, all patients were safely and efficiently managed by laparoscopic cholecystectomy during the 72 golden hours with no intraoperative complications recorded, $0 \%$ convergence rate, all discharged home on the first postoperative day, and none had postoperative complications. Moreover, a literature review of clinical studies evaluating laparoscopic cholecystectomy during initial hospitalization for acute calculous cholecystitis revealed that it was associated with reduced hospital stays, lower morbidity and mortality rates. ${ }^{4-6}$ In addition, laparoscopic cholecystectomy was reported to be an efficient surgical option to treat gangrenous cholecystitis with low conversion rate $(8.7 \%)$ and a decrease in mortality and morbidity rates. ${ }^{13}$ On the other hand, the delay in admission and treatment was reported to be a considerable factor in the subsequent development of gangrenous cholecystitis. ${ }^{8}$

The results of gangrenous cholecystitis also showed that $74(63.2 \%)$ male patients developed gangrene of the gallbladder compared to only 43 (36.8\%) female patients. Consequently, it showed a significant association of the male
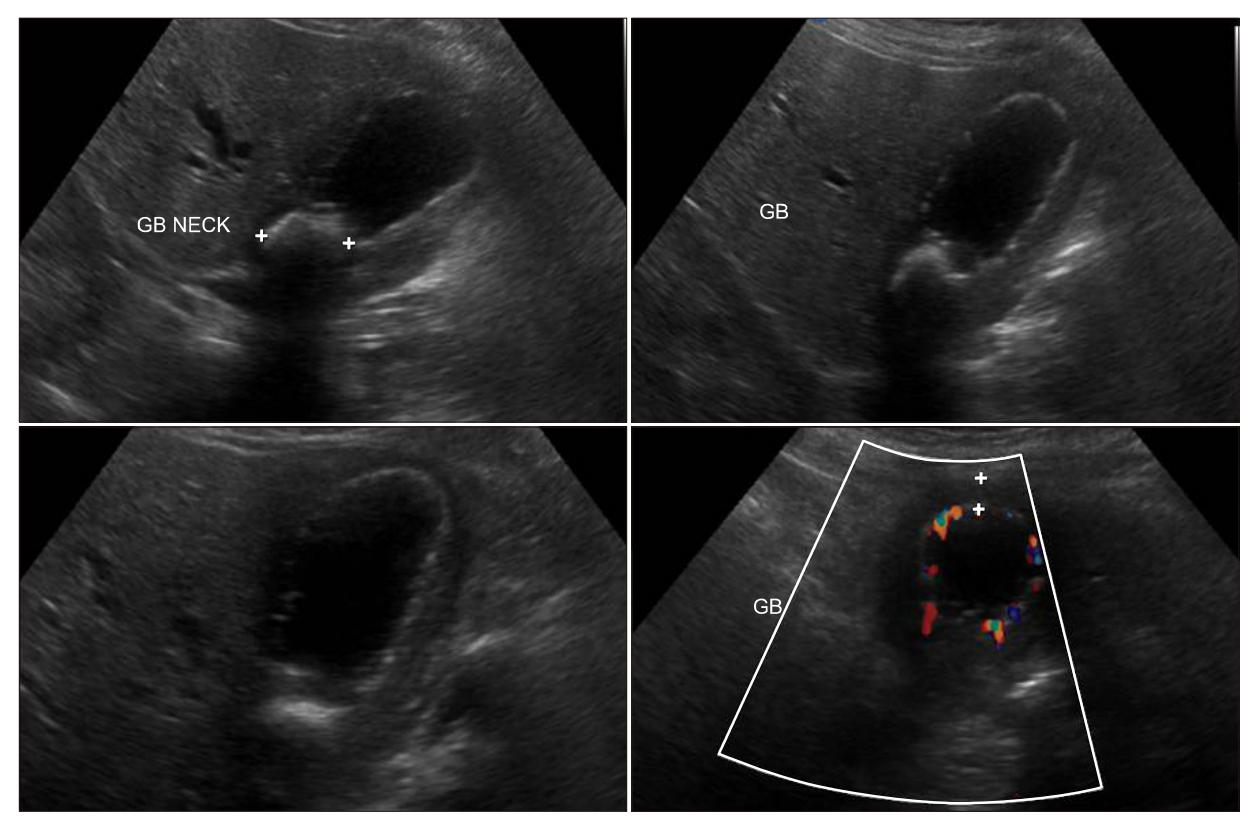

Fig. 1. Ultrasound of the abdomen showing a large gall stone measuring $25 \mathrm{~mm}$ impacted at the gallbladder neck with moderate dilatation of the gallbladder. The wall of the gallbladder is markedly thickened measuring $8.8 \mathrm{~mm}$. The mucosa of the gallbladder is echogenic and hypervascular. 
gender $(p=0.04)$. Many published papers reported similar association. ${ }^{1,3,14}$ Another predictive factor in our study results which was found statistically to be associated with gangrene is leukocytosis $>15,000$ cells $/ \mathrm{ml}(p=0.03)$. One of the first studies to report the association between leukocytosis and gallbladder gangrene was Merriam et al. ${ }^{1}$ in $1999\left(17,000 / \mathrm{mm}^{3}\right)$. In addition, Fagan et al. ${ }^{10}$ and Aydin et al. ${ }^{15}$ reported that $\mathrm{WBC}$ count $>15,000 / \mathrm{mm}^{3}$ predicted the development of gangrenous cholecystitis.

Ultrasound of the gallbladder is the radiological method of choice for detecting acute calculous cholecystitis. The sonographic criteria includes thickening of the gallbladder walls more than $3 \mathrm{~mm}$, ultrasonographic Murphy's sign, "railway" signs on the gallbladder wall, and distension of the gallbladder more than $5 \mathrm{~cm}$ on its transversal diameter. ${ }^{16}$ In our study, ultrasound was the only imaging technique used as an emergency diagnostic tool. Consequently, our study results pointed out that sonographic gallbladder wall thickness 5.1-6 mm $(p=0.01)$ and more than $6 \mathrm{~mm}(p=0.01)$ showed a significant relation to gangrene of the gallbladder. Many other studies also reported the significance of sonographic gallbladder wall thickness as a major sign for gangrenous gallbladder in acute cholecystitis (Fig. 1). ${ }^{14,17,18}$

In our study, age $\geq 40$ years was found statistically to be a predictive value for gangrene gallbladder for both males and females $(p=0.04)$. Other studies reported that old age $(>40$ and $>50)$ is an independent risk factors predicting development of gangrenous cholecystitis. ${ }^{2,3,9,10}$ In addition, diabetes mellitus was found statistically to be a predictive value for gangrene gallbladder for both males and females $(p=0.02)$. It has been postulated that the cystic artery pathologies resulting from atherosclerosis or microvascular diseases could lead to vascular insufficiency, thus, predisposing factor such as diabetes mellitus could be considered as a risk factor in the development of gangrenous cholecystitis. ${ }^{10,19}$ In fact, we observed in our series that patients with diabetes mellitus who developed gangrene as a complication of acute calculous cholecystitis had a worse clinical course in the form of aggressive presentation, difficult surgery, and more complicated postoperative outcome. Therefore, we can state that the association of diabetes mellitus with acute calculous cholecystitis was the strongest predictive factor in gangrenous gallbladder among our patients compared to the other factors. Yacoub et al. ${ }^{14}$ offered a scoring system determining gangrenous cholecystitis probability by using clinical and laboratory variables like age, gender, heart rate, white blood cell count, and gallbladder wall thickness. Wu et al. ${ }^{18}$ tested Yacoub's variables and proposed a 5-point scoring system depending on variables like age, white blood cell count, gallbladder wall thickness, pericholecystic fluid, and American Society of Anesthesiology score of $>2$ in which 0 points result in a $2 \%$ probability of gangrenous cholecystitis and 5 points indicates a $63 \%$ probability. Our study also identified variables like age, gender, wall thickness, leukocytosis in addition to diabetes mellitus to be strong predictors of gangrenous cholecystitis. Though we did not propose any scoring system, we noticed that in our series, $4(3.4 \%)$ patients had two variable as positive predictors at emergency presentation, $14(12 \%)$ had three variables, 29 (24.8\%) had four variables, and the majority $70(59.8 \%)$ had all five variables. A single variable was not scored at all.

We believe that the current trends in developing evidence-based predicting factors, scoring systems, and diagnostic help tools are of great value in the quest to provide the best possible medical care to the patients including the accuracy of diagnostic help tools, the urgency to operate, precautions to be considered in the operating theater, and the need for intensive care postoperatively. We recommend for more scientific studies to be encouraged to look for other factors and tools.

We conclude that gallbladder sonographic wall thickness 5.1-6 mm, more than $6 \mathrm{~mm}$, male gender, diabetes mellitus, leukocytosis $>15,000$ cells $/ \mathrm{ml}$, and age $\geq 40$ years were found to be factors predisposing to gangrene complicated acute calculous cholecystitis that represented a statistically significant difference. By implementing these risk factors, patients urgency for surgery can be decided in the emergency department. Other risk factors like high alanine aminotransferase, elevated aspartate aminotransferase, and high alkaline phosphatase could be of help in the decision-making for early operation.

\section{REFERENCES}

1. Merriam LT, Kanaan SA, Dawes LG, Angelos P, Prystowsky JB, Rege RV, et al. Gangrenous cholecystitis: analysis of risk factors and experience with laparoscopic cholecystectomy. Surgery 1999;126:680-685; discussion 685-686.

2. Bedirli A, Sakrak O, Sözüer EM, Kerek M, Güler I. Factors ef- 
fecting the complications in the natural history of acute cholecystitis. Hepatogastroenterology 2001;48:1275-1278.

3. Stefanidis D, Bingener J, Richards M, Schwesinger W, Dorman J, Sirinek K. Gangrenous cholecystitis in the decade before and after the introduction of laparoscopic cholecystectomy. JSLS 2005; 9:169-173.

4. Contini S, Corradi D, Busi N, Alessandri L, Pezzarossa A, Scarpignato C. Can gangrenous cholecystitis be prevented?: a plea against a "wait and see" attitude. J Clin Gastroenterol 2004; 38:710-716.

5. Papi C, Catarci M, D'Ambrosio L, Gili L, Koch M, Grassi GB, et al. Timing of cholecystectomy for acute calculous cholecystitis: a meta-analysis. Am J Gastroenterol 2004;99:147-155.

6. Siddiqui T, MacDonald A, Chong PS, Jenkins JT. Early versus delayed laparoscopic cholecystectomy for acute cholecystitis: a meta-analysis of randomized clinical trials. Am J Surg 2008;195: 40-47.

7. Miyazaki K, Uchiyama A, Nakayama F. Use of ultrasonographic risk score in the timing of operative intervention for acute cholecystitis. Arch Surg 1988;123:487-489.

8. Thornton DJ, Robertson A, Alexander DJ. Patients awaiting laparoscopic cholecystectomy--can preoperative complications be predicted? Ann R Coll Surg Engl 2004;86:87-90.

9. Bourikian S, Anand RJ, Aboutanos M, Wolfe LG, Ferrada P. Risk factors for acute gangrenous cholecystitis in emergency general surgery patients. Am J Surg 2015;210:730-733.

10. Fagan SP, Awad SS, Rahwan K, Hira K, Aoki N, Itani KM, et al. Prognostic factors for the development of gangrenous cholecystitis. Am J Surg 2003;186:481-485.
11. Ganapathi AM, Speicher PJ, Englum BR, Perez A, Tyler DS, Zani S. Gangrenous cholecystitis: a contemporary review. J Surg Res 2015;197:18-24.

12. Önder A, Kapan M, Ülger BV, Oğuz A, Türkoğlu A, Uslukaya Ö. Gangrenous cholecystitis: mortality and risk factors. Int Surg 2015; 100:254-260.

13. Hunt DR, Chu FC. Gangrenous cholecystitis in the laparoscopic era. Aust N Z J Surg 2000;70:428-430.

14. Yacoub WN, Petrosyan M, Sehgal I, Ma Y, Chandrasoma P, Mason RJ. Prediction of patients with acute cholecystitis requiring emergent cholecystectomy: a simple score. Gastroenterol Res Pract 2010;2010:901739.

15. Aydin C, Altaca G, Berber I, Tekin K, Kara M, Titiz I. Prognostic parameters for the prediction of acute gangrenous cholecystitis. J Hepatobiliary Pancreat Surg 2006;13:155-159.

16. De Vargas Macciucca M, Lanciotti S, De Cicco ML, Coniglio M, Gualdi GF. Ultrasonographic and spiral CT evaluation of simple and complicated acute cholecystitis: diagnostic protocol assessment based on personal experience and review of the literature. Radiol Med 2006;111:167-180.

17. Yeh DD, Cropano C, Fagenholz P, King DR, Chang Y, Klein EN, et al. Gangrenous cholecystitis: deceiving ultrasounds, significant delay in surgical consult, and increased postoperative morbidity! J Trauma Acute Care Surg 2015;79:812-816.

18. Wu B, Buddensick TJ, Ferdosi H, Narducci DM, Sautter A, Setiawan L, et al. Predicting gangrenous cholecystitis. HPB (Oxford) 2014;16:801-806.

19. Shpitz B, Sigal A, Kaufman Z, Dinbar A. Acute cholecystitis in diabetic patients. Am Surg 1995;61:964-967. 